
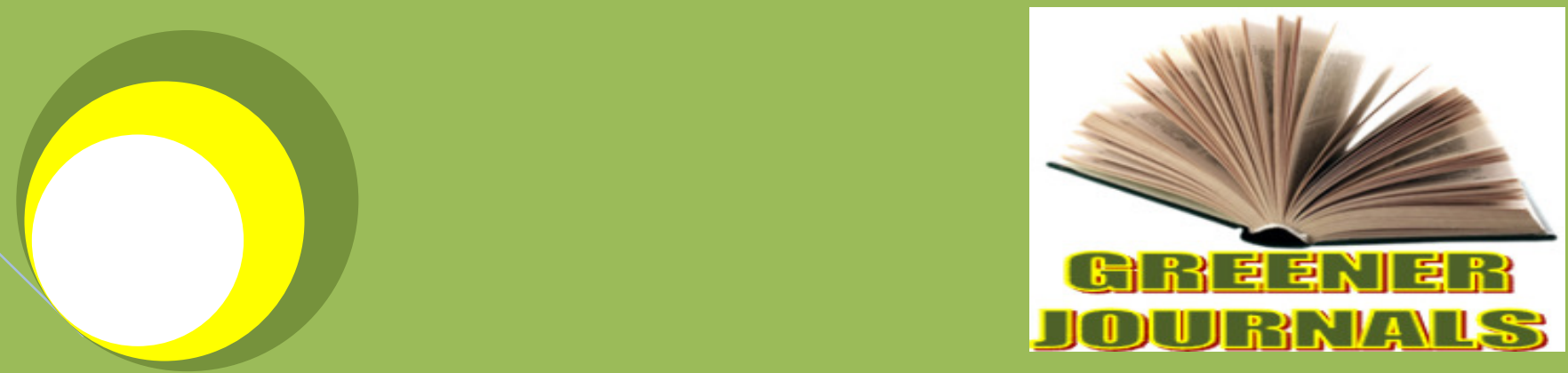

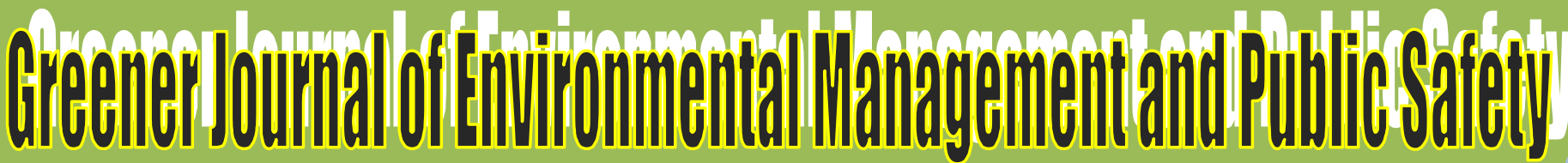

ISSN: 2354-2276

Lead Content of Lichens in Metropolitan Harare, Zimbabwe. Air Quality and Health Risk Implications

By

Mupa M.

Dzomba P.

Musekiwa C.

Muchineripi R. 


\title{
Lead Content of Lichens in Metropolitan Harare, Zimbabwe. Air Quality and Health Risk Implications
} Mupa M. ${ }^{1}$, Dzomba P. ${ }^{1 *}$, Musekiwa C. ${ }^{1}$, Muchineripi R. ${ }^{2}$

\author{
${ }^{1}$ Chemistry Department, Faculty of Science, P. Bag 1020, Bindura, Zimbabwe. \\ ${ }^{2}$ Biological sciences Department, Faculty of Science, P.O. Box MP 167, Mt Pleasant, Harare, Zimbabwe. \\ *1Corresponding Author Email: pdzomba@gmail.com or pdzomba@buse.ac.zw
}

\begin{abstract}
Many studies have shown that inhaled lead is one of the major contributors of lead poisoning. Lead poisoning affects all systems within the body. Lead amount in metropolitan Harare atmosphere was estimated by measuring the amount of lead in lichens found in the area. Lead pollution of the atmosphere is of major concern because continuous exposure of low levels of lead may cause serious effects. Furthermore there are no agreed safety limits for children. The concentration of $\mathrm{Pb}$ in different species was determined by atomic absorption spectrometry. Lead concentration varied from not detectable quantities to $3.31 \pm 0.04 \mathrm{ppm}$. Harare central hospital recorded the highest lead content $3.31 \pm 0.04$ ppm in Parmelia species while the lowest was observed at centers far from the CBD, Botanic gardens, Christonbank and Mwenje dam. Generally the relationship between distance, lead content and species diversity was significant for most lichens except that for Lecanora caesiopallens $(r=0.72)$ and Lecanora atraaeformis $(r=0.71)$ student $t$-test $p>0,05$ showing presence of increased pollution in the CBD. It is suggested that all possible sources of lead poisoning and their contributions to atmospheric lead content should be ascertained to determine the actual daily exposure rate. Such data would help in formulating policies to reduce lead poisoning in the general public.
\end{abstract}

Keywords: Lead content, lichens, air quality, health implications.

\section{INTRODUCTION}

Exposure to low levels of lead through contaminated air has adverse health implications (Ferner 2001; Jarup 2003; Arora et al. 2008). Most importantly, it is the long-term effects of lower levels of lead exposure that cause concern. Many studies have shown that heavy metals such as lead are extremely persistent in the environment. They are non biodegradable and therefore they can readily accumulate to toxic levels (Grzebsz et al 2002; Ma et al 2001; Adie and Osibanjo 2009; Bergamasdini et al. 2004). Long-term exposure may result in general fatigue, headaches, blood circulation problems, reduced kidney function, reduced fertility, reduced brain function and other neurological problems (Ogwuegbu and Muhanga 2005). Children are considered to be mostly affected than adults to the effects of lead WHO, (1995). It has been widely recognized that lead at exposure levels well below those mentioned for acute lead poisoning has the potential to impair children's brain development and learning (Navas-Acien et al. 2007). Lead is also harmful to adults. Adults can suffer from, reproductive problems for both men and women, high blood pressure and hypertension, nerve disorders, memory and concentration problems and muscle and joint pain (Wilson, 2008; Lanntech, 2004). Many countries have successfully enacted laws and regulations to limit the use of leaded petrol, however the developing world including Zimbabwe have been slow in enforcing such laws. Worldwide leaded petrol has been implicated as the major source of lead poisoning in human beings (Luilo and Othman 2006). Other sources of lead contamination include paints and street dust. The quantity of the lead absorbed by humans via the lungs depends on the concentration of lead in the environment. Chronic lead poisoning occurs when small amounts of lead are taken in over long periods of time. Exposure to lead is most commonly monitored by measuring blood lead levels (Schwartz and Hu 2007; Menke et al. 2006; Kosnett and Wedeen 2007; Hu et al. 2007; AOEC 2007), however long term exposure can rarely be ascertained from blood lead records. No one in general population has an adequate blood measurement history. The ability of lichens to absorb and accumulate xenobiotics makes them useful as indicators of air quality (Mimis et al. 2002; Bargagli and Mikhailova 2002; Garty, 2001). They depend on surface absorption of nutrients. Lichens lead measurements allow the direct measurement of long term lead exposure. At present little is known about the range of chronic environmental exposure to the general population in Harare. Thus this study has the potential to give an insight on the effects of low levels of lead exposures. 


\section{MATERIALS AND METHODS}

All reagents were analytical grade. $\mathrm{HNO}_{3}$ and $\mathrm{HClO}_{4}$ were obtained from Merck, New Jersey, USA. Calibration and Certified reference materials were obtained from Aldrich, Steinheim, Germany. Double deionized water was used for all analysis. Analysis of heavy metal content was performed using AAS, Varian model AA 1275 series atomic absorption spectrophotometer equipped with a single slot burner and a built in digital read out.

\section{Sampling Sites}

Samples were collected from five sampling stations along a 47,5km transect in the city of Harare. The five sampling stations were Harare Kopje, Harare central hospital National Botanic gardens, Christonbank and Mwenje dam. Harare Kopje is located in the heart of the Central Business District (CBD) while Harare central hospital is entirely surrounded by factories. The National Botanic Gardens are located in a low density residential area while Christonbank and Mwenje Dam are in the outskirts of the CBD.

\section{Sample collection}

Samples were collected from trees of the same species (Brachystegia) of approximately the same age as determined by their diameters. Samples were collected at face height $\pm 15 \mathrm{~cm}$ using a pocket knife into clean labeled polythene bags and transported straight to the laboratory. Fifty trees were sampled from each area. The lichens were identified by taxonomist from the Harare National herbarium. Some species could only be identified by the family only.

\section{Sample preparation}

Samples were washed with minimum deionized water and shade dried for two weeks. Dried lichens were then ground in a hand mill to a uniform size by sieving through a $2 \mu \mathrm{m}$ sieve. A mass of $1 \mathrm{~g}$ of each lichen species was weighed into a flask and $21 \mathrm{ml}$ of $6: 1$ mixture of concentrated $\mathrm{HNO}_{3}$ and $15 \% \mathrm{HClO}_{4}$ was added. Five replicate samples were prepared for each species for each area. The mixture was gently heated to $80^{\circ} \mathrm{C}$ and then the temperature was raised to $150^{\circ} \mathrm{C}$ to achieve complete dissolution. The final solution was filtered into $50 \mathrm{ml}$ flasks and diluted to the mark with $2 \mathrm{M} \mathrm{HNO}_{3}$. Lead concentration in the species was determined using an atomic absorption spectrophotometer.

\section{Quality assurance and quality control}

Suitable quality control and assurance protocols were carried out to ensure reliability of the results. Double deionized water was used throughout the study. Glassware was properly cleaned, and the reagents used were of analytical grade. Reagents blank determinations were used to correct the instrument readings. All analyses were performed five times. Certified reference materials (CRM) were used for validation of the analytical procedure. The results of measurements of CRMs are summarized in Table 1.

Table 1. Certified reference material concentrations (ppm) mean $\pm S D, n=5$

\begin{tabular}{llll}
\hline Sample & $\begin{array}{l}\text { Certified } \\
\text { value }\end{array}$ & $\begin{array}{l}\text { Measured } \\
\text { value }\end{array}$ & $\begin{array}{l}\text { Recovery } \\
(\%)\end{array}$ \\
\hline CRM 1 & $120 \pm 0,6$ & $119 \pm 0,5$ & 99 \\
CRM 2 & $73 \pm 0,5$ & $73 \pm 0,5$ & 100 \\
\hline
\end{tabular}

\section{Statistical analysis}

Data gathered from different sampling area were subjected to (ANOVA) and separation of means was done using Duncan test at $p<0.05$ of SPSS Version 16.0 (SPSS Inc., Chicago, IL, USA) with replications as random effects. Spearmen product correlation moment $(r)$ and Student $t$ test at 0.05 significant level was applied to determine relationships between lead concentration with distance and species diversity. 


\section{RESULTS AND DISCUSSION}

Lichens have long been recognized as sensitive indicators of environmental pollution (Adams et al 2007; Turhan et al 2005; Ekmekyapar et al. 2006). Application of lichens as bioindicators of air quality is one of the suitable methods to monitor heavy metals in cities. There is a very close statistical relationship between heavy metal contents in lichens and the heavy metal pollution measured in air Coskun, (2006). Biomonitoring studies provide valuable information about the quantity and quality of pollutants in the atmosphere and can be very effective as an early warning system to detect environmental changes (Bajpai et al. 2004).

\section{Lead concentration and number of lichen species at each site}

Two lichens species were found at Harare Kopje while one was observed at Harare central hospital (Fig 1 and 2). At Harare Kopje lead content was found to be $1.81 \pm 0.08 \mathrm{ppm}$ in Parmelia species and $2.17 \pm 0.01 \mathrm{ppm}$ in Pseudoparmelia species Fig 1. Harare hospital recorded the highest lead content of $3.31 \pm 0.04$ in Parmelia species Fig 2.

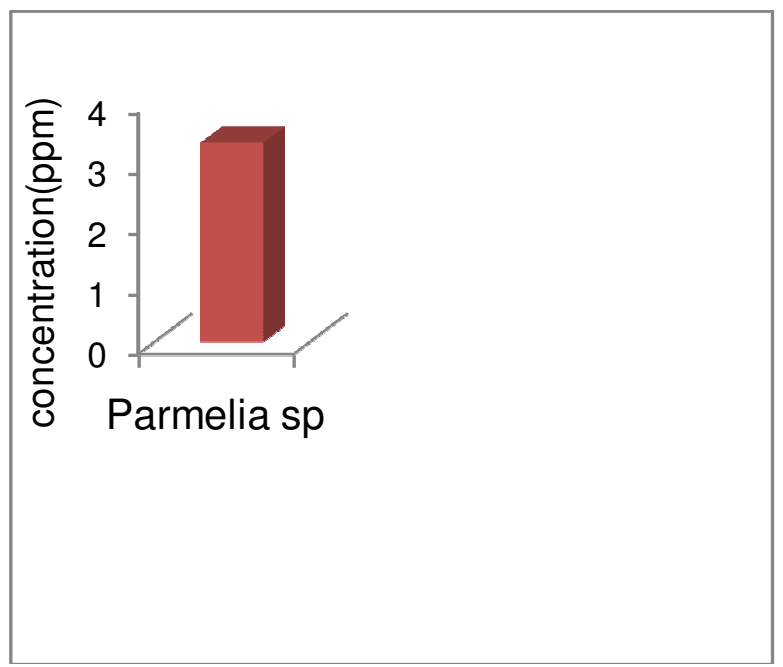

Fig 1. Harare Kopje

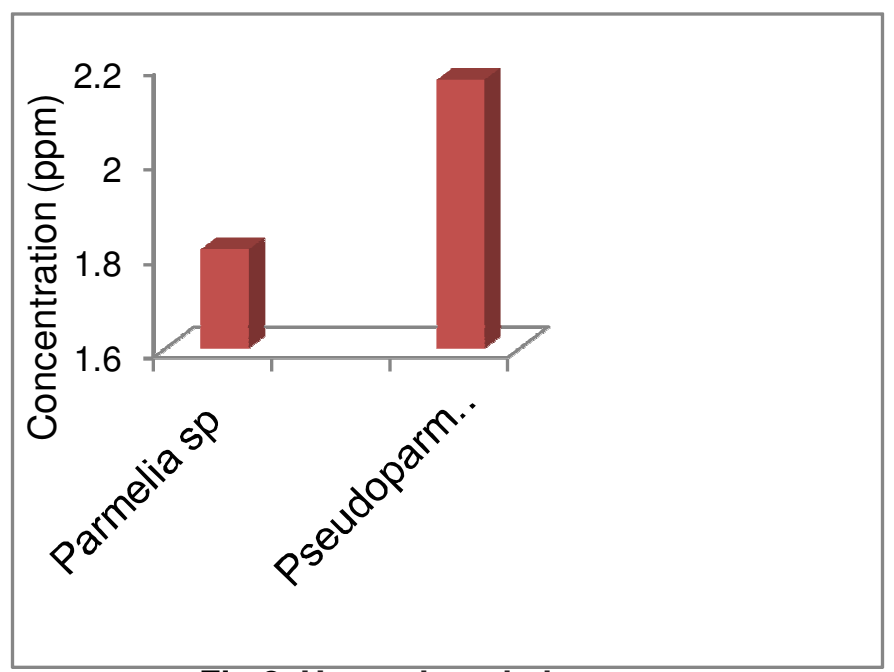

Fig 2. Harare hospital

Five lichens species were observed at Harare botanic gardens Fig 3 . Lead content was found to be $1.31 \pm 0.07$ in Parmelia sp, $1.40 \pm 0.01$ in Pseudoparmelia sp, $1.57 \pm 0.07$ in Lecanora Caesiopallens while Usnea sp and Cladonia digitata levels were beyond detectable limits Fig 3.

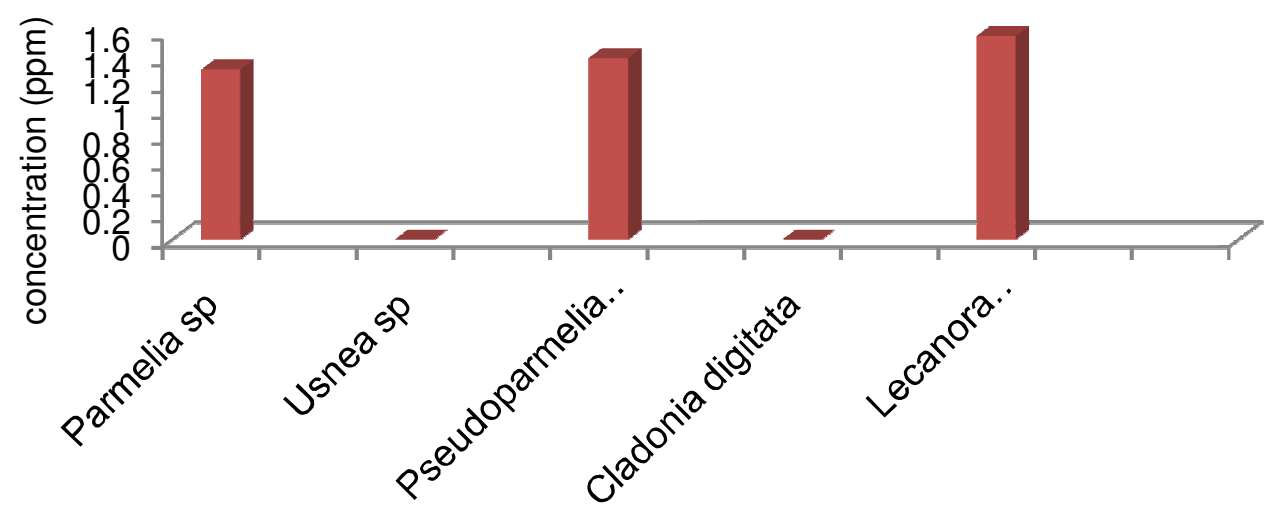

Fig 3. Botanic gardens 
A total of eight lichen species were recorded at Christonbank site Fig 4. Lichens lead content varied from $0.46 \pm 0.06$ to $1.10 \pm 0.07$. Lecanora atraaeformis recorded the highest levels while Parmelia species recorded the lowest. Usnea, Cladonia Digitata and Lecanora ostracoderma lead content were not detectable.

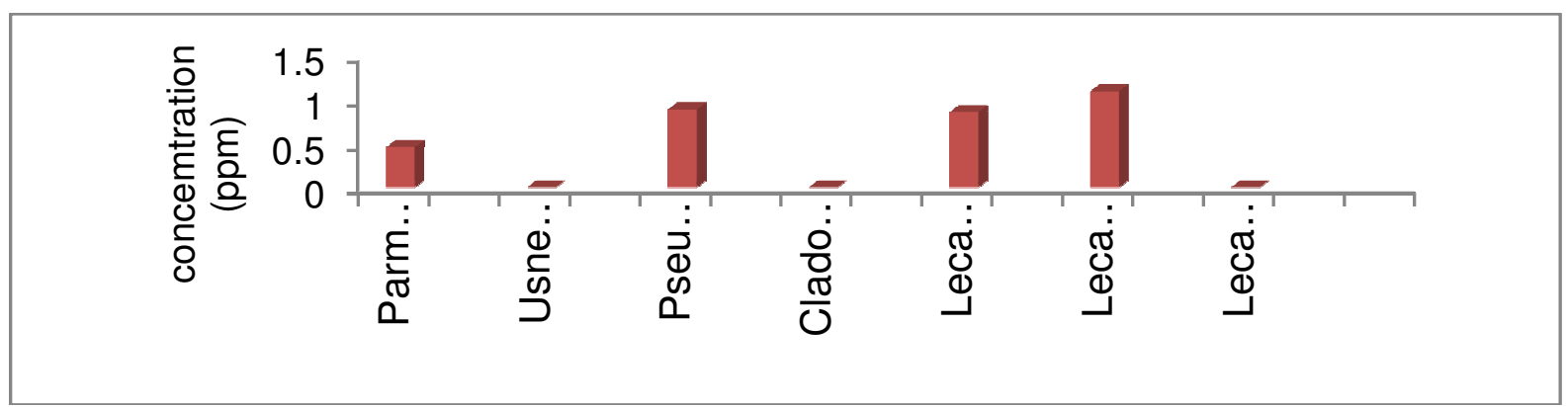

Fig 4. Christonbank

Among all the areas studied Mwenje Dam recorded the highest number of species Fig 5. A total of 10 species were observed. Lead levels ranged from $0.19 \pm 0.06$ in Parmelia to $0.67 \pm 0.07$ in Lecanora atraaeformis. Levels in Usnea sp, Cladonia Digitata ,Lecanora ostracoderma, Dirinaria sp, Parmeliopsis sp and Lobaria sp were beyond detectable limits.

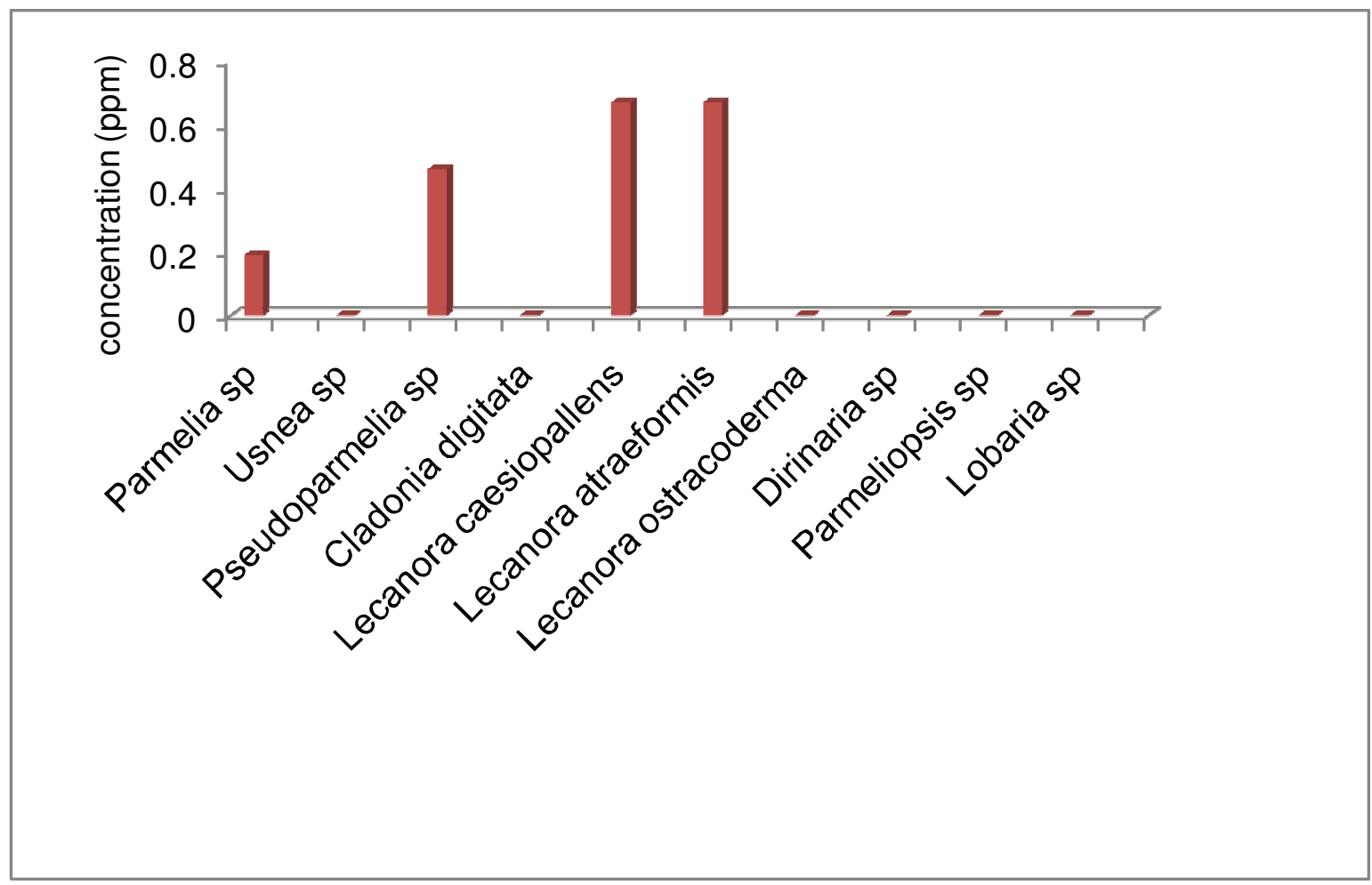

Fig 5. Mwenje Dam

Lichen species diversity increased with increase in distance from the CBD from 1 to 10 Fig 6. Parmelia species were present in all the selected areas while Lecanora species favored areas far from the CBD where lead levels were low. 


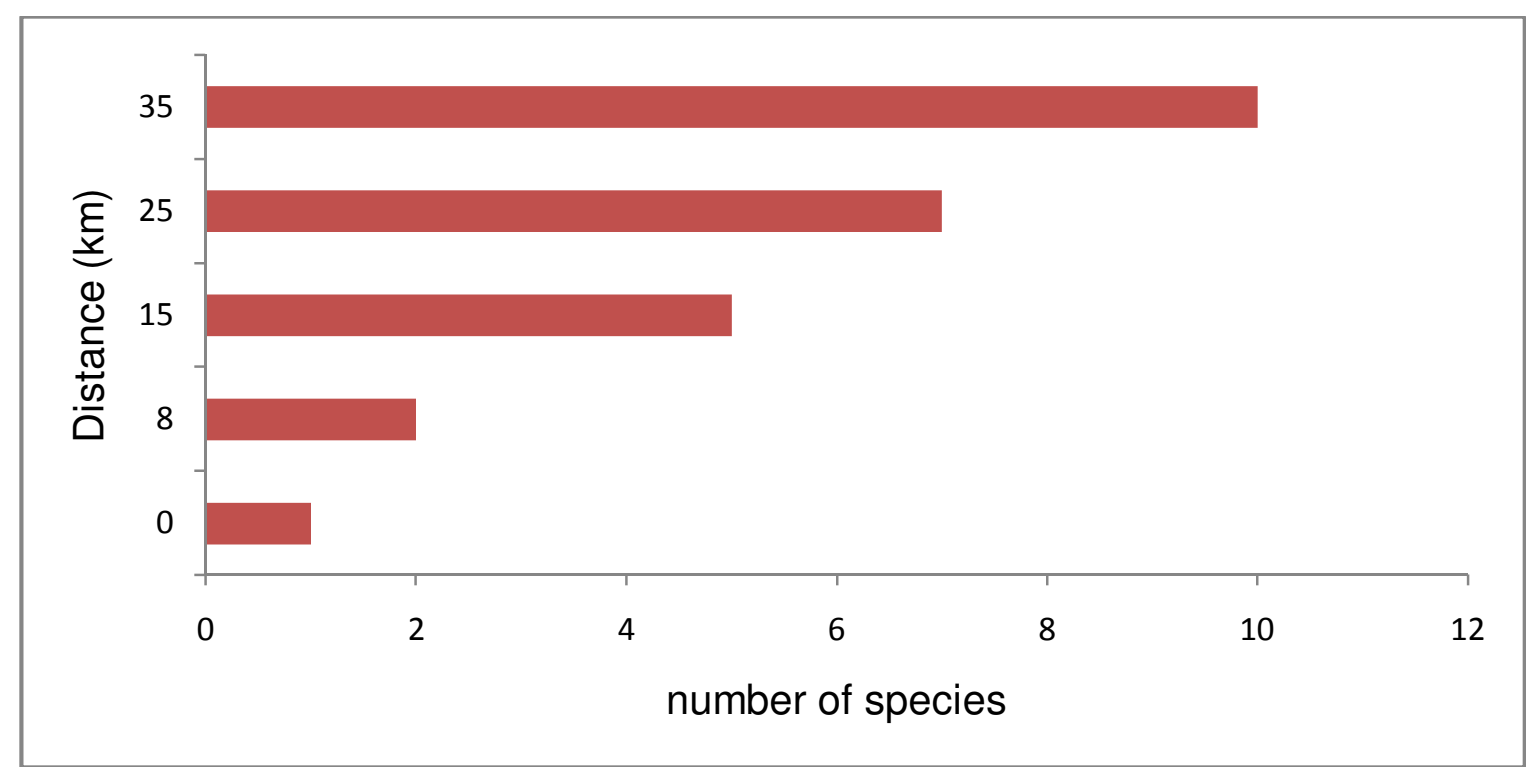

Fig 6. Diversity of lichens in relation to distance from the CBD

Generally the relationship between distance and species diversity was significant for most lichens (Table 1) except that for Lecanora caesiopallens $(r=0.72)$ and Lecanora atraaeformis $(r=0.71)$ student t-test $p>0.05$. The increase in the diversity of lichens on Brachystegia trees with distance from the CBD was also reported by (Hawksworth and McManus 1989; Carreras and Pignata 2007). In both cases the number of species in all substrates declined along a $10 \mathrm{~km}$ transact towards the city centre. Reported values were significantly correlated to lead concentration in lichen thalli. In the present study levels of lead were significantly related to distance and species diversity for most of the lichens student t-test $p>0.05$. Lawrey, (2011) observed that lichen communities in urban parks closest to Washington, DC were lowest in species diversity and coverage, and had no pollution-sensitive species.

Table 1 Correlation between distance and lead concentration (A), distance and species diversity (B) and species diversity and lead concentration $(C) P=0,05$

\begin{tabular}{|l|l|l|l|}
\hline Species & A & B & C \\
\hline Parmelia sp & 0.89 & 0.94 & 0.90 \\
\hline Usnea sp & & 0.99 & \\
\hline Pseudoparmelia sp & 0.83 & 0.84 & 0.87 \\
\hline Cladonia digitata & & 0.87 & \\
\hline Lecanora caesiopallens & 0.92 & $0.72^{*}$ & 0.95 \\
\hline Lecanora atraeformis & $0.32^{*}$ & $0.71^{*}$ & 0.90 \\
\hline Lecanora ostracoderma & & 0.95 & \\
\hline Dirinaria sp & & 0.99 & \\
\hline Parmeliopsis sp & & 0.96 & \\
\hline Lobaria $s p$ & & 0.94 & \\
\hline
\end{tabular}

${ }^{*}=$ no significant difference, $p=0.05$, Student t-test.

\section{Air quality and Health implication}

Lichens are widely used for biomonitoring of atmospheric heavy metals (Bargagli and Mikhailova 2002; Garty, 2001; Adams et al 2007; Turhan et al 2005; Ekmekyapar et al. 2006; Yazıcı and Aslan 2006; Bingol et al. 2009). There is very close statistical relationship between the accumulated heavy metals in lichens and the heavy metal pollution measured in air (Monna et al. 2012 ; Bajpai et al. 2011; Herzig 1993; Sloof and Wolterbeek 1998). Lichen species develop structural changes in response to air pollution that may include reduced photosynthesis and bleaching. 
Pollution can result in the death of the lichen algae, reduced growth of the lichen fungus, or kill the lichen completely. With time all sensitive species may be replaced by pollution tolerant species. Therefore it follows that the species of lichens present in an area and the concentration of pollutants measured in those lichens can tell us a lot about air quality. The presence of lead in lichen thallus exhibits its airborne origin. Quantities of lead absorbed via the lungs by humans depend on the concentrations of lead in the air through which a person passes in the course of a day.

Presence and distribution of lichens in Harare show that the air in Harare is polluted with lead. High levels of lead in lichens around Harare central hospital can be rationalized by increased pollution from cars and industries surrounding the area. Species diversity in this area was greatly diminished as compared to other areas. Levels of lead decreased significantly with increasing distance from the CBD (ANOVA $p>0.05$ ). Several studies share similar results as found in this research. Gombert et al. (2003) found out that lichen species diversity diminished around polluted sites. High levels of pollution eventually kill the lichens and only those species that can tolerate such levels survive. Health implications of high levels of lead in the air refer to the harmful effects of lead to the body when being consumed above the bio-recommended limits. Recent studies have shown that the magnitude of change in blood lead of adults caused by changes in concentration of lead in inhaled air show that for every $1 \mu \mathrm{g}$ of $\mathrm{Pb}$ per $\mathrm{m}^{3}$ of air contributes $0.3 \mu \mathrm{g} \mathrm{Pb} / 100 \mathrm{~g}$ of blood. World Health Organization (1995) task force basing on the analysis of occupational data reported that each $1 \mu \mathrm{g} \mathrm{Pb}$ per $\mathrm{m}^{3}$ of breathed air contributes about $1 \mathrm{~g} \mathrm{~Pb}$ per100 $\mathrm{g}$ of blood.

There is no definite relationship reported for children. Some studies have found out that average intake of lead from air appears to be below quantities that are thought to produce adverse health effects (Navas-Acien et al. 2007). Constant exposure of low levels of lead can lead to harmful effects because of its teratogenic effect. Lead poisoning also inhibits the synthesis of haemoglobin; disturb the well functioning of kidneys, joints, reproductive systems, cardiovascular and the Central Nervous System (Ogwuegbu and Muhanga 2005). Lichens are very important as bioindicators of air pollution because they assist in the interpretation of epidemiological patterns of respiratory diseases.

\section{CONCLUSION}

The presence of lead metal in lichens and the significant correlation between distance from the CBD, lead concentration in lichens and species diversity generally indicate the presence of lead in the ambient air of metropolitan Harare. The presence of lead in the atmosphere is now of greater concern because many studies have found out that average intake of lead from air appears to be below quantities that are thought to produce adverse health effects. Long-term exposure of low levels of lead may result in fatigue, headaches, blood circulation problems, reduced kidney function, reduced fertility, reduced brain function and other neurological problems. Furthermore the actual permissible safe limit in children is not certain. Because of presence of lead in the atmosphere as shown by lichens, it is therefore important to conduct further monitoring of the quality of foods grown or prepared in Harare and water sources. All possible sources of lead poisoning and their contribution should be ascertained to determine the actual daily exposure rate. Such data would help in formulating policies to reduce lead poisoning of the population in cities. It may also be useful to map the overall contribution of other pollutants such as $\mathrm{SO}_{2}$ and other heavy metals to improve the accuracy of the findings.

\section{ACKNOWLEDGEMENT}

The authors thank University of Zimbabwe technicians for an excellent technical assistance and AA measurements throughout this work.

\section{REFERENCES}

Adamo, P., Crisafulli, P., Giordano, S., Minganti, V., Modenesi, P., Monaci, F., Pittao, E., Tretiach, M., Bargagli, R (2007). Lichen and moss bags as monitoring devices in urban areas. Part II: Trace element content in living and dead biomonitors and comparison with synthetic materials. - Environ. Pollut. 146: 392-399.

Adie GU and Osibanjo O (2009). Assessment of soil-pollution by slag from an automobile Battery manufacturing plant in Nigeria. Afr. J. Environ. and application. Crit. Rev. PI. Sci., 20, 309-371.

AOEC (2007). Medical Management Guidelines for Lead-Exposed Adults Revised 04/24/2007 Sourced from the Association of Occupational and Environmental Clinics (AOEC) - http://www.aoec.org/principles.htm

Arora Monu., Bala Kiran., Shweta Ran.i, Anchal Ran.i, Barinder Kaur., Neeraj Mittal (2008). Heavy metal accumulation in vegetables irrigated with water from different sources. Food Chemistry 111: 811-815 
Bajpai, R., D.K. Upreti and S.K. Mishra (2004). Pollution monitoring with the help of lichen transplant technique at some residential sites of Lucknow. J. Environ. Biol., 25, 191-195.

Bajpai, R., Upreti D.K., Mishra S.K., Mohabe S (2011). Determination of atmospheric heavy metals using two lichen species in Katni and Rewa cities, India. J. Environ. Biol., 25, 191-199.

Bargagli and Mikhailova (2002). Accumulation of inorganic contaminants. Monitoring with lichens. Earth and environmental science. 7: (84) 6-5

Bergamaschi, L., E. Rizzio., G. Giaveri., A. Profumo., S. Loppi and M. Gallorini (2004). Determination of baseline element composition of lichens using samples from high elevations. Chemo., 55, 933-939.

Bingol A., Aslan, A., Çakıcı A (2009). Biosorption of chromate anions from aqueous solution by a cationic surfactantmodified lichen (Cladonia rangiformis (L.). J. Hazard. Mater., 161: 747-752.

Carreras, H.A. and M.L. Pignata (2002): Biomonitoring of heavy metals and air quality in Còrdoba City, Argentina, using transplanted lichens. Environ. Pollut., 117, 77-87

Coskun, M (2006). Atmospheric deposition of heavy metals in Thrace studied by analysis of Austrain Pine (Pinus nigra) needle. Bull. Environ. Conta. Toxic., 76, 320-326.

Ekmekyapar F., Aslan A., Kemal Bayhan Y., Cakici A (2006). Biosorption of copper (II) by non living lichen biomass of Cladonia rangiformis Hoffm. J. Hazard. Mater., B137: 293-298.

Ferner, D J (2001). Toxicity, heavy metals. eMed. J., 2(5): 1. Institute of Environmental Conservation and Research INECAR, Position Paper Against Mining in Rapu-Rapu. 2001; Published by INECAR, Ateneo de Naga University, Philippines www.adnu.edu.ph/Institutes/Inecar/pospaper1.asp.

Garty, J (2001). Biomonitoring atmospheric heavy metals with lichens: Theory and application. Crit. Rev. PI. Sci., 20, 309-371.

Gombert S., Asta M.R.D., Seaward S (2003). Correlation between the nitrogen concentration of two epiphytic lichens and traffic density in an urban area. Environmental pollution.123. 281-290.

Grzebisz W., Ciesla L., Komisarek J., Potarzycki J (2002). Geochemical assessment of heavy metals pollution of urban soils. Polish J. Environ. Stud., 11(5): 493-499.

Hawksworth, D.L. and McManus, P.M. (1989). Lichen recolonization in London under conditions of rapidly falling sulphur dioxide levels, and the concept of zone

skipping. Bot. J. Linn. Soc. 100:99-109.

Herzig, R (1993). Multi-residue analysis with passive biomonitors: A new approach for volatile multi-element contents, heavy metals and polycyclic aromatic hydrocarbons with lichens in Switzerland and the Principality of Liechtenstein. In Plants as Biomonitors- Indicators for Heavy Metals in the Terrestrial Environment. B. Markert (Ed.), VCH-Publishers, Weinheim, Basel. 285-328. http://www.ehponline.org/docs/2006/9782/abstract.html/ http://www.pubmedcentral.nih.gov/articlerender.fcgi?artid=1849918.

$\mathrm{Hu}, \mathrm{H}$., Shih, R., Rothenberg S., Schwartz, BS (2007). The Epidemiology of Lead

J. Environ. Biol., 25, 191-195 (2004).

Jarup,L.(2003).Hazards of heavy metal contamination. British Medical Bulletin.; 68, 167-182. doi:10.1093/bmb/ldg032.

Kosnett, M.J and Wedeen, R.P (2007). Recommendations for Medical Management of Adult Lead Exposure. Minimonograph. Environmental Health Perspectives, 115 (3)

Lawrey, J.D. (2011). A lichen biomonitoring program to protect resources in the National Capital Region by detecting air quality effects. Natural Resource Program Center, Fort Collins, CO. NRTR NPS/ NCRN/NRTR -- 2011/450. https://nrinfo.nps.gov/Reference.mvc/

Lenntech (2004). Water Treatment and Air Purification. Published by Lenntech, Rotterdamseweg, Netherlands www.excelwater.com/thp/filters/Water Purification.htm.

Luilo G.B and Othman O.C (2006). Lead pollution in urban roadside environments of Dar es Salaam city Tanz. J. Sci. Vol 32(2) 62-69.

Ma L.Q., Komar K.M., Tu C., Zhang W., Cai Y., Kenelly E.D (2001). A fern that Hyper accumulates arsenic. Nature, 409: 579-582.

Menke, A., Munter, P., Batuman, P.V., Silbergeld E., Guallar, E (2006). Blood lead below 10 ug/dL and Mortality among US Adults. Journal of the American Heart Foundation. Circulation 114; 1388 - 1394; originally published online Sep 18, 2006.

Monna, F., Lhoussaine Bouchaou., Claire Rambeau., Rémi Losno., Olivier Bruguier., Gaetano Dongarrà., Stuart Black., Carmela Chateau (2012). Lichens Used as Monitors of Atmospheric Pollution around Agadir (Southwestern Morocco)_A Case Study Predating Lead-Free Gasoline. Water Air Soil Pollution (2012). 223:1263-1274

Navas-Acien A., Guallar E., Silbergeld E (2007). Rothenberg SJ. Lead exposure and cardiovascular disease a systematic review. Environ Health Perspect 115:472-82.

Nimis, P.L., C. Scheidegger., P. Wolseley (2002). Monitoring with lichens Monitoring lichens, Kluwer, Dordrecht . 
Ogwuegbu, M.O.C., Muhanga, W (2005). Investigation of Lead Concentration in the Blood of People in the Copper belt Province of Zambia J. Environ. ; (1): 66-75.

Schwartz, BS and Hu, H (2007). Adult Lead Exposure: Time for Change. Environmental Health Perspectives,Minimonograph 115(3); 451-454.

Sloof J.E, Wolterbeek H (1998). National trace element. Air pollution monitoring survey using epiphytic lichens. The lichenologist 23 (2): 139-165.

Turhan K., Ekinci-doğan C., Akcin, G., Aslan A (2005). Biosorption of AU (III) and from Aqueous Solution by a NonLiving Usnea Longissima Biomass. Fresenius Environ. Bull., 14(12a): 1129-1135.

WHO, World Health Organization, (1995). Environmental Health Criteria 165: Inorganic Lead, Geneva: International Programme on Chemical Safety. World Health Organization, Geneva.

Wilson, L., (2008). The Dangers of Toxic Metals. Retrieved from: http://www.dreddyclinic.com/dangers-of-toxicmetals.htm.

Yazıcı K., Aslan A (2006). Distribution of Epiphytic Lichens and air pollution in the City of Trabzon, Turkey. Bull. Environ. Contamination

Toxicol. 77: 838-845. 